\title{
Genomics Approaches for Studying Musical Aptitude and Related Traits
}

\author{
Järvelä, Irma \\ Oxford University Press Pakistan \\ 2018-10
}

Järvelä , I 2018 , Genomics Approaches for Studying Musical Aptitude and Related Traits .

in $\mathrm{M} \mathrm{H}$ Thaut \& D A Hodges (eds), The Oxford Handbook of Music and Neuroscience.

Oxford Handbooks Online , Oxford University Press Pakistan , pp. 439-458 . https://doi.org/10.1093/oxfordhb/97801

http://hdl.handle.net/10138/312694

https://doi.org/10.1093/oxfordhb/9780198804123.013.18

unspecified

acceptedVersion

Downloaded from Helda, University of Helsinki institutional repository.

This is an electronic reprint of the original article.

This reprint may differ from the original in pagination and typographic detail.

Please cite the original version. 
Genomics approaches for studying musical aptitude and related traits

Irma Järvelä

Department of Medical and Clinical Genetics, University of Helsinki, P.O. Box 63, 00014 University of Helsinki, Finland

*Address for correspondence and proofs:

Irma Järvelä MD, PhD

Department of Medical and Clinical Genetics

University of Helsinki, Box 720

00251 Helsinki, FINLAND

E-mail: irma.jarvela@helsinki.fi

Fax: (09) 19125105 


\begin{abstract}
Although music and other forms of art can develop in diverse directions, they are linked to the genetic profiles of populations. Analysis of music related human traits using the methods of genomics revealed that genetic loci containing genes for inner ear development, auditory pathways and cognition are linked to musical aptitude. Analysis of the human transcriptome after listening to music and music performance plus genome wide analysis of the selection regions in the human genome uncovered the activities of genes affecting hearing, birdsong, cognition and language development. These data suggest that music and language share a common evolutionary background. In addition, identification of several genes (e.g. SNCA, RGS2, RGS9) known to contribute to dopaminergic metabolism support the role of the dopaminergic pathway as a mediator of the effects of music in the human body.
\end{abstract}

Key words: birdsong, cognition, dopamine, evolution, gene, genome wide analysis, inner ear development, music, musical aptitude, transcriptome 


\section{Genomic approaches to study human traits}

Each cell in human body contains 46 chromosomes, made up of $\sim 3$ billion nucleotides containing about 20,000 individual genes (Dixon-Salazar \& Gleeson 2010). Of the 20000 genes, to date the functions of 4000 genes have been uncovered (www.omim.org). About $1.5 \%$ of the genome encodes amino acids that form the building blocks of human tissues and organs, the proteins. The human cerebral cortex is made up of $\sim 20$ billion neurons, each of which makes an average of 7,000synaptic contacts (Dixon-Salazar \& Gleeson 2010). The human brain exhibits a higher expression of genes for synaptic transmission and plasticity and higher energy metabolism compared to other primates (Cáceres et al 2004). The genomic approaches enable the study of biological phenomena in an unbiased and hypothesis-free fashion, without any knowledge of the biological background of the phenotype of interest (Lander 2011). Molecular genetic analyses can be applied to study human traits based on their molecular properties rather than anatomic regions. The utility of next generation sequencing technology has facilitated the identification of individual genetic variants ("genetic selfies") with decreasing cost (Lindor et al, 2017). This has been exemplified in medical research, where thousands of genes that cause inherited diseases or predisposition to common diseases have been identified.

Molecular genetic studies are based on Mendelian rules, knowing that children inherit half of their genes from their mother and half from their father. The inherited variants remain the same during their entire lives. This is the unique strength of DNA studies in the identification of genetic variants associated with human traits. Using statistical methods genetic loci and alleles can be identified in the human genome that are associated with the trait under study. Genes with their pathways located in the associated regions are the candidate genes whose functions can explain the biological characteristics of a trait under study. Environmental factors (life-style) can affect the expression and regulation of genes. The effect of the environmental triggers on the expression and regulation of the genes can be studied for example by RNA- and microRNA-sequencing in humans and model organisms. Methods of genomics and bioinformatics can be applied to combine the above data to identify genes and alleles, their regulation and pathways linked to musical aptitude and music-related behavioral traits (e.g. music education, listening, performing, creating music). 


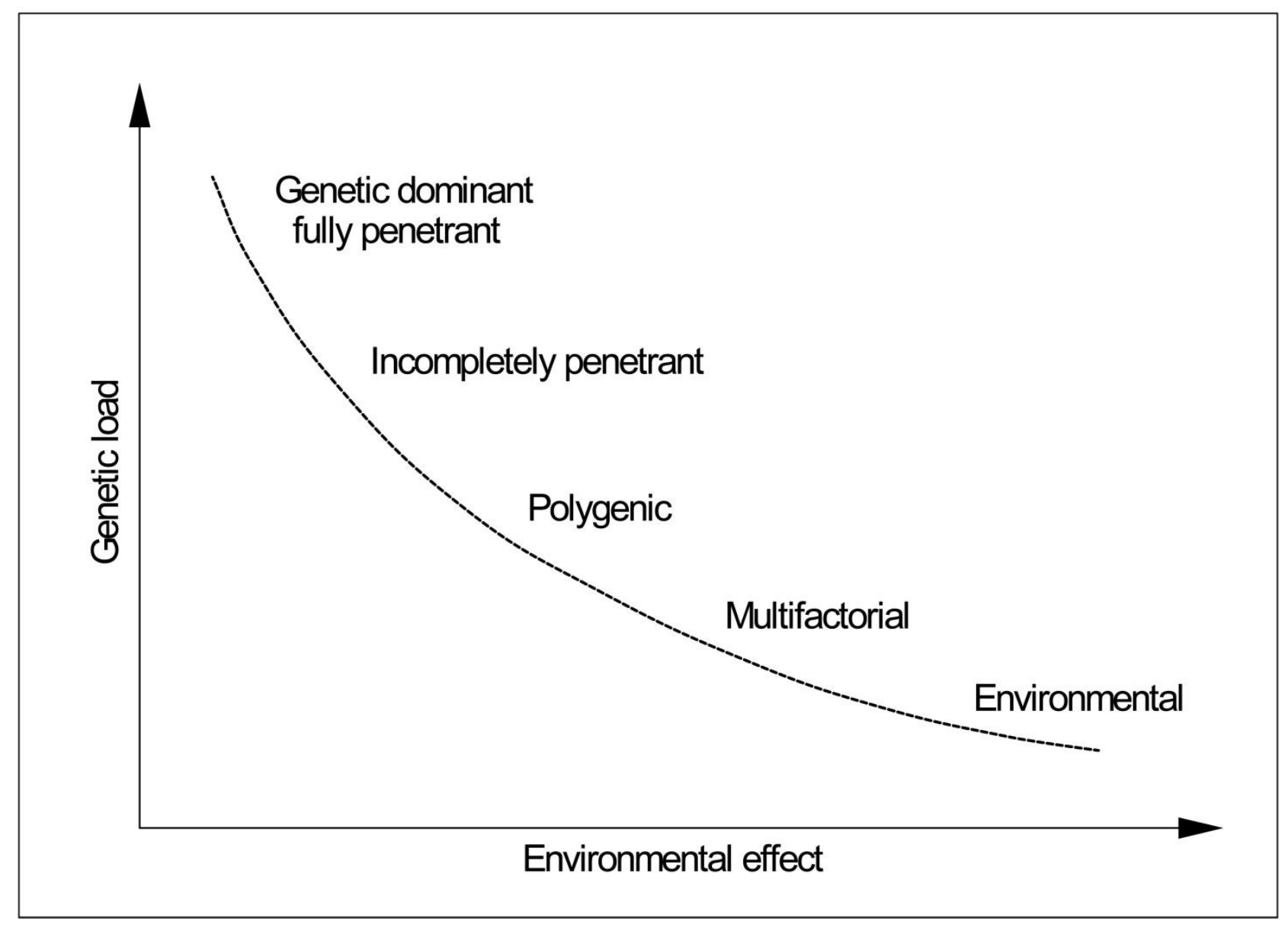

Figure 1. The mode of inheritance of human traits spans from monogenic, i.e. caused by a single gene to multifactorial inheritance caused by numerous predisposing variants and environmental factors. Based on genetic and genomics studies musical aptitude is inherited as a multifactorial trait for which both predisposing genetic variants and exposure to music as an environmental factor are needed (Pulli et al 2008; Park et al 2012; Oikkonen et al 2015).

\section{Musical aptitude as a biological trait}

Musical practices represent distinctive cognitive abilities of humans. In biological (genetic) terms, musical aptitude represents a complex cognitive trait in humans where the function of the auditory pathway (inner ear, brain stem, auditory cortex) and several brain regions are involved. Music is sound that is recognised by hair cells in the inner ear. These sounds are transmitted as electrical signals through the midbrain to the auditory cortex. About $1 \%$ of all human genes have a function in hearing, of them at least 80 are known to cause hearing loss (http://hereditaryhearingloss.org/) ( Atik et al 2017). Brains are naturally very sensitive to environmental exposure to music (Perani et 
al, 2010) and music training (see e.g. Herholz and Zatorre 2012; Koelsch 2010). This sensitivity is age-dependent similarly to language (White et al, 2013, Penhune \& de Villers-Sidani 2014) or vocal learning in songbirds (Rothenberg et al 2014). The sensitivity may be linked to emotional content characteristic to musical sounds that have their effect on human body functions (Nakahara et al 2011, Salimpoor et al 2011). However, the molecular mechanisms and biological pathways mediating the effects of music remain largely unknown.

It may be that the ability to detect musical sounds serves as a prerequisite for appreciating music. This ability is called musical aptitude in this article. Musical aptitude can include abilities, for example, to perceive and understand intensity, pitch, timbre and tone duration, and the rhythm and structure they form in music. Carl Seashore has developed a battery of tests consists of six subtests that measure pitch, intensity, time, consonance, tonal memory, and rhythm (Seashore et al, 1960). The Seashore tests for pitch (SP) and for time (ST) consist of pair-wise comparisons of the physical properties of sound, and are used to measure simple sensory capacities such as the ability to detect small differences in tone pitch or length. Karma has developed a test to measure the structure of music that includes recognition of melodic contour, grouping, relational pitch processing (Karma 1994). The auditory structuring ability can be defined as the ability to identify temporal aspect in time (detecting sound patterns in time) (Karma 1994). Similar kind of pattern recognition is found in many other fields like sport and poetry (comprising language and speech) that resembles "gestalt principles" in recognition of music structure (Justus and Hutsler 2005). In zebra finches, identification of acoustic features of song syllables (pitch and timbre) and the species specific typical gap durations (rhythm) between song syllables are detected by different neural cells (Araki et al 2017). Temporal coding of intersyllable silent gaps seems to preserved when birds are exposed to different song environments suggesting that temporal gap coding is innate and species specific whereas syllable morphology coding is more experience dependent (Araki et al, 2017). In fact, the detection of gaps resembles the detection of pauses in music structure in humans. This is related to understanding tones with time that evokes anticipatory responses because of the cognitive expectations and prediction cues involved in listening to music (Salimpoor et al., 2015). In fact, combined music test scores (KMT; SP, ST) were normally distributed among participants with no specific music education (Oikkonen and Järvelä 2014) suggesting that the ability to detect pitch, time and sound patterns is common in populations with no music training. Abilities that animals exhibit without the need for training are referred to innate traits. The possession of a natural musical ability may explain why musical practices are common and present in all societies. 
It has been observed that musicianship clusters in families. How much is this aggregation due to genetic and/or environmental factors, exposure to music? Several studies have been performed to analyse the inheritance of musical traits. In a twin study using a Distorted Tunes Test (DTT) (the subjects' task was to recognize wrong tones incorporated into simple popular melodies) the correlation between the test scores was 0.67 in monozygous and 0.44 in dizygous twins (Drayna et al, 2001). The heritability (defined as the proportion of the total variance of the phenotype that is genetic, h2=VG/VP, where VG is genetic variance and VP is the overall variance of the phenotype) of the auditory structuring ability test (Karma Music Test, KMT) was 0.46 in the Finnish families examined (Oikkonen et al, 2015). Carl Seashore's subtests of pitch (SP) and time discrimination (ST) measure the ability to detect small differences between two sequentially presented tones. The heritability scores are 0.68 and 0.21 for SP and ST, respectively. The heritability of combined KMT, SP and ST scores COMB was 0.60 (Oikkonen et al, 2015). The heritability of pitch perception test (PPA) that is based on singing was $40 \%$ (Park et al, 2012). A genetic component has also been demonstrated in rare music phenotypes such as congenital amusia and absolute pitch (AP) (Perez et al, 2007; Baharloo et al, 2000). Congenital amusia is often referred to as "tone deafness" and is a disorder in which a subject's ability to perceive or produce music is disturbed. A recent family aggregation study showed that the sibling relative risk $\left(\lambda_{\mathrm{S}}\right.$, ) was estimated to be 10.8 , which suggests a genetic contribution to the trait (Peretz et al., 2007). Another extreme trait is absolute pitch (AP). AP refers to the ability to identify and name pitches without a reference pitch, and the sibling relative risk $\left(\lambda_{s}\right)$ has been estimated to range from 7.8 to 15.1 (Baharloo et al, 2000). In fact, music perception belongs to a class of human cognitive abilities that has been shown to be highly familial. In the Finnish families, $52 \%$ of the professional musicians had one or both parents who were also professional musicians (Figure 2). 


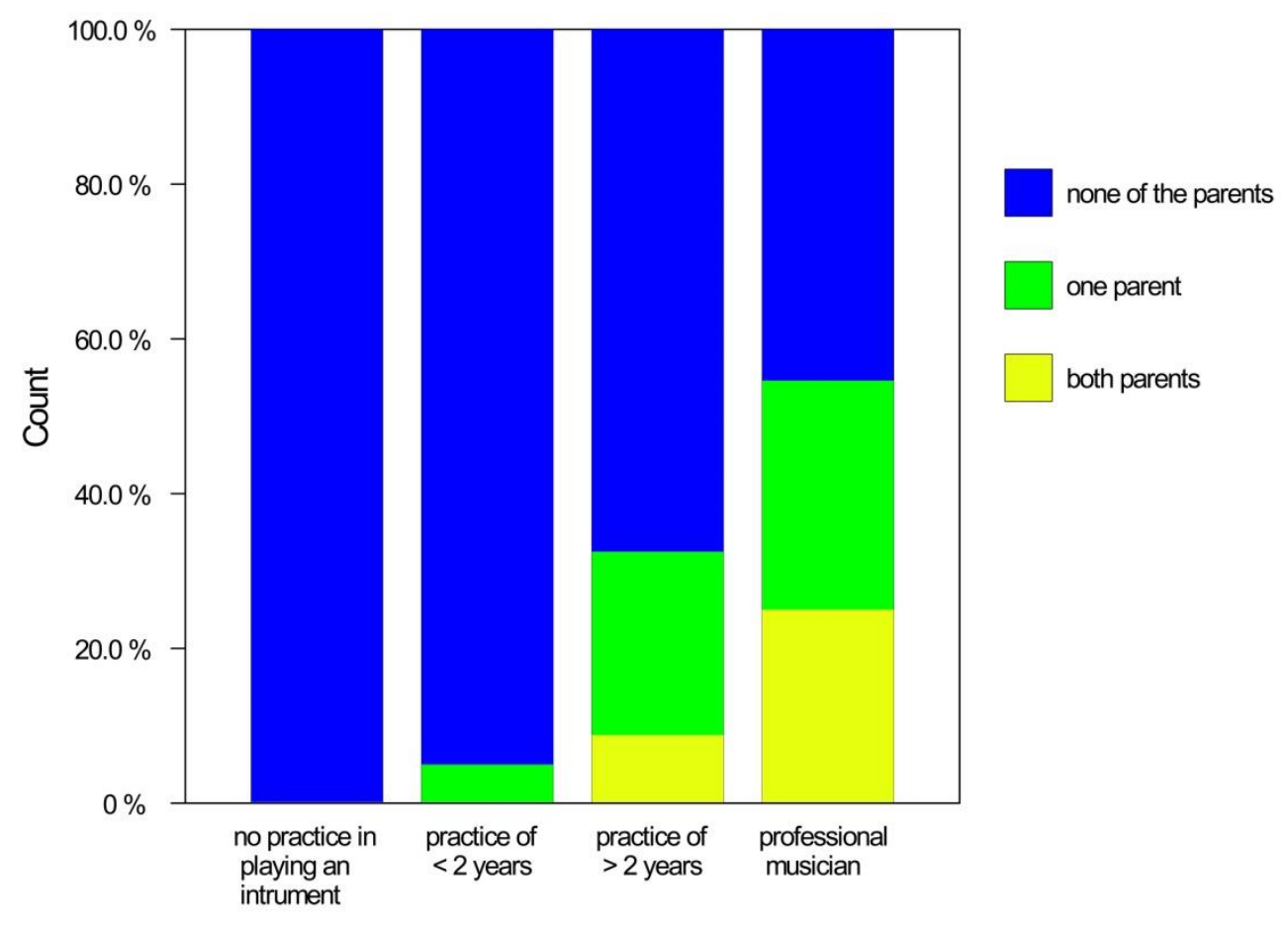

Figure 2. Parental music education is related to children's music education. High music education is common among parents of professional musicians $(n=100)$. With permission from Petri O Peltonen.

\section{Evolution of musical aptitude}

Evolution is based on genetic alleles that are transmitted through generations during history. Music cultures can develop in diverse directions but they are linked to the genetic alleles in the human genome. These alleles are responsible for biological determinant human traits. Favourable alleles are enriched in the gene pool showing high allele frequencies associated with the beneficial trait, whereas damaging alleles that cause harmful effects tend to disappear from the gene pool. The universality of music in all societies suggests that beneficial alleles do underlie music-related behaviour. However, it is not known what distinguishes humans from primates with regard to musical ability and what are the biological determinants underlying artistic cognitive traits.

It is notable that modern humans have an auditory centre that functions identically to that of the first primates that lived millions of years ago (Parker et al 2013). Adaptive convergent sequence evolution has also been found in echolocating bats and dolphins (Montealegre et al 2012), implicating that numerous genes are linked not only to hearing but also vision. Interestingly, several birdsong genes were shown to be upregulated when listening to and performing music (Guo et al. 2007; Horita et al.2012; Kanduri et al, 2015a, 2015b; Pfenning et al 2014). These data suggest that the machinery to facilitate the hearing of sounds is highly conserved. It facilitates 
communication via sounds important for the survival of humans and other species. Vocal learning in song birds shows similar features to those found humans (Araki et al 2017). Recent studies on songbirds have shown that there exist two different types of brain cells in the bird auditory cortex, these register song syllables in zebra finches (Araki et al 2017). One type identifies the acoustic features of song syllables (pitch and timbre) that are affected more by the environment whereas the other type detects the species specific typical gap durations (rhythm) between song syllables which are preserved (Araki et al, 2017).

Advanced cognitive abilities are characteristic of humans and are likely to be more the recent result of positive selection (Sabeti et al 2006). For example, FOXP2 has been implicated in human speech and language has been under positive selection during recent human evolution (Enard et al 2002). As genetic evolution is much slower than cultural evolution, we and others (Honing et al 2015) hypothesize that the genetic variants associated with musical aptitude have a pivotal role in the development of music culture. In comparison, in songbirds, the evolution of song culture is the result of a multigenerational process where the song is developed by vertical transmission in a species-specific fashion suggesting genetic constraints (Lipkind andTchernichovski 2011). This emphasizes the importance of the selection of parental singing skills and their genetic background in evolution.

According to the Mendelian rules half of the genes are directly inherited to the offspring. In fact, genetic component is larger as the other half of the genes that are not transmitted to the children shape the parental behaviour and affect the children's development. Concordantly, Hambrick et al 2014 have shown that training music is responsible for about 30\% of music performance in professional musicians implying that other factors including genes have a larger effect. In a Swedish twin study it was found that willingness to practice music is an independent personality trait that has a high heritability (40-70\%) (Mosing et al 2014). These results point to a greater and independent role of genetic factors contributing to music perception and practice.

Genomic approaches can be used to identify the regions of positive selection in the human genome. Variations in the music test scores of auditory structuring ability (Karma Music Test; KMT), Carl Seashore's subtests of pitch (SP) and time discrimination (ST) suggest that the alleles may have been targeted for selection. When testing three methods for selection, haplotype based methods haploPS, XP-EHH, and the allele frequency based method $\mathrm{F}_{\mathrm{ST}}$ in the combined phenotype of three 
music test scores shown above (COMB), hundreds of genes were found in the selection regions (Liu et al, 2016). Several of them were known to be involved in auditory perception and inner ear development (DICER1, FGF20, CUX1, SPARC, KIF3A, TGFB3, LGR5, GPR98, PAX8, COL11A1, USH2A, PROX1). The findings are consistent with the convergent evolution of genes related to auditory processes and communication in other species (Montealegre-Z et al, 2012; Parker et al, 2013; Zhang et al, 2014). Some genes were known to affect cognition and memory (e.g. GRIN2B, $I L 1 A, I L 1 B, R A P G E F 5)$ and reward mechanisms (RGS9). Interestingly, several genes were linked to song perception and production in songbirds (e.g, FOXP1, RGS9, GPR98, GRIN2B, VLDLR). Of these GPR98 expressed in the song control nuclei of the vocalizing songbird (zebra finch) has been found to be under positive selection in the songbird lineage (Pfenning et al., 2014).

Some hypothesis could be constructed based on previous biological knowledge about the identified genes. FOXP2 has been implicated in an inherited language disorder (Lai et al, 2001) that causes disturbances in the ability to detect timing (rhythm) but not pitch in music (Alcock et al, 2000). This is concordant with the different brain cells that are responsible for pitch and timing in songbirds (Araki et al, 2017). FOXP1 and another candidate gene VLDLR, a direct target gene of human FOXP2 (Vernes et al, 2007; Ayub et al, 2013), belong to the singing-regulated gene networks in the zebra finch. VLDLR, very-low-density lipoprotein receptor (Vldlr) is a member of the Reelin pathway, which affects learned vocalization (Hilliard et al, 2012). GRIN2B is associated with learning, brain plasticity and cognitive performance in humans (Kauppi et al. 2011) and belongs to the 10 prioritised genes in convergent analysis of musical traits in animals and humans (Oikkonen et al 2016).

$R G S 9$ is expressed in the striatum and belongs to the regulator of G-protein signalling (RGS) gene family that play a key role in regulating intracellular signalling of G-protein coupled receptors, such as dopamine. The data support the previous findings of the role of dopaminergic pathway and its link to the reward mechanism as molecular determinants in the positive selection of music (Salimpoor et al, 2011). This preliminary study identified a huge amount of functionally relevant candidate genes which underlie the evolution of music. Further studies may give a more accurate picture after methods to analyse polygenic selection become available (Qian et al, 2013).

\section{Genome-wide linkage and association analyses of musical traits}


For assigning genetic markers associated with a trait such as musical aptitude the definition of the phenotype is required. As musical aptitude is a complex cognitive trait, it is likely that its individual components have distinct molecular backgrounds. Each of these component (subphenotype) can be analysed separately and they can also be combined.

In a genome wide study of musical aptitude nearly 800 family members were defined for auditory structuring ability (Karma Music Test, KMT) (Karma 1994) and perception of pitch and time (Seashore 1960) in music and a combined test score of all the three aforementioned test scores (COMB). When the family material was analysed for 660000 genetic markers several genetic loci were found in the human genome (Oikkonen et al., 2015). The identified loci contained candidate genes that affect inner ear development and neurocognitive processes, which are necessary traits for music perception. The highest probability of linkage was obtained at 4q22 (Oikkonen et al 2015). Earlier, chromosome $4 q 22$ was found in a smaller family material using microsatellite marker scan (Pulli et al 2008). The strongest association (in unrelated subjects) was found upstream of GATA binding protein 2 (GATA2) at chromosome 3q21.3. GATA2 is a relevant candidate gene as it regulates the development of cochlear hair cells (Haugas et al 2010) and the inferior colliculus (IC) (Lahti et al 2013) important in tonotopic mapping i.e., the processing of sounds of different frequency in the brain. Interestingly, GATA2 is abundantly expressed in dopaminergic neurons (Scherzer et al, 2008) that release dopamine during emotional arousal to music (Salimpoor et al, 2011). Several plausible candidate genes were located at 4 p14 with the highest probability of linkage in the family study (Oikkonen et al 2015). The pitch perception accuracy (SP) was linked next to the protocadherin 7 gene (PCHD7), expressed in the cochlear (Lin et al., 2012) and amygdaloid (Hertel et al., 2012) complexes. PCHD7 is a relevant candidate gene for pitch perception functioning in the hair cells of the cochlea that recognize pitches (Gosselin et al, 2007). The amygdala is the emotional centre of the human brain affected by music (Koelsch 2010). Interestingly, the homologous gene $\mathrm{PCDH} 15$ also affects hair cell sensory transduction and together with cadherin type 23 ( $\mathrm{CDH} 23)$ ( another candidate gene at chromosome 16 ) form a tip-link with each other in sensory hair cells (Sotomayor et al., 2012). Moreover, the Pcdha -gene cluster was found in the CNV-study of musical aptitude (Ukkola-Vuoti et al, 2013). Platelet-derived growth factor receptor alpha polypeptide (PDGFRA) is expressed in the hippocampus (Di Pasquale et al, 2013), associated with learning and memory. The potassium channel tetramerisation domain containing 8 (KCTD8) is expressed in the spiral ganglion of the cochlea (Metz et al 2011). KCTD8 also interacts with the GABA receptors $G A B R B 1$ and $G A B R B 2$, of these, GABRb1 protein is reduced in schizophrenia, bipolar disorder and major depression, diseases that severely affect 
human cognition and mood regulation (Fatemi et al, 2013). Cholinergic receptor, nicotinic alpha 9 (neuronal) (CHRNA9) (Katz et al, 2004) and the paired-like homeobox 2b (PHOX2B) (Ousdal et al, 2012) on chromosome 4 also affect inner ear development. In addition, $P H O X 2 B$ increases amygdala activity and autonomic functions (blood pressure, heart rate, and respiration) that are reported to be affected by music (Blood \& Zatorre 2001). The genome-wide analyses performed on Mongolian families using the pitch perception accuracy (PPA) test identified a partly shared genetic region on chromosome 4q (Park et al, 2012). The statistically most significant locus found in a genome-wide linkage study of absolute pitch (AP) is located at 8q24.21 (Theusch et al, 2008). The results suggest that musical aptitude is an innate ability that is affected by several predisposing genetic variants (Figure 1).

Genome-wide copy number variation (CNV) analysis revealed regions that contain candidate genes for neuropsychiatric disorders were associated with musical aptitude (Ukkola-Vuoti et al, 2013). A deletion covering the protocadherin-a gene cluster 1-9 (PCDHA 1-9) was associated with low music test scores (COMB) both in familial and sporadic cases. PCDHAs affect synaptogenesis and maturation of the serotonergic projections in the brain and Pcdha mutant mice show abnormalities in learning and memory (Katori et al 2009).

\section{The effect of music perception and performance on human transcriptome}

Music acts as an environmental trigger. Numerous studies have shown that listening to and performing classical music has an effect on the human body (Blood \& Zatorre 2011; Salimpoor et al, 2011). When comparing genome wide RNA expression profiles before and after listening to classical music and after a "music-free" control session, the activity of genes involved in dopamine secretion and transport (SNCA, RTN4, and SLC6A8), learning and memory (SNCA, NRGN, NPTN, RTN4) were enhanced (Kanduri et al., 2015a). Of these genes, SNCA (George et al 1995), NRGN (Wood et al 2008) and RGS2 affect song learning and singing in songbirds (Clayton 2000) suggesting a shared evolutionary background of sound perception between vocalizing birds and humans. It is noteworthy that the effect of music was only detectable in musically experienced listeners. The lack of the effect of music in novices could be explained by differences in the amount of exposure to music that is known to affect brain structure and function (Elbert et al, 1995; Gaser and Schlaug 2003), unfamiliarity with the music (Salimpoor et al, 2009), or musical anhedonia (Martínez-Molina et al, 2016). In addition, listening to music increased the expression of the target 
genes of the dopaminoceptive neuronal glucocorticoid receptor ( $N R 3 C 1)$, which increases the synaptic concentration of dopamine linked to rewarding and reinforcing properties (Ambroggi 2009). It is of note that $N R 3 C 1$ is also a key molecule in the regulation of addictive behaviour.

Music performance by professional musicians involves a wide-spectrum of cognitive and multisensory motor skills, whose molecular basis is largely unknown. The effect of music performance on the genome-wide peripheral blood transcriptome of professional musicians was analysed by collecting RNA-samples before and after a 2-hr concert performance and after a 'music-free' control session. The up-regulated genes were found to affect dopaminergic neurotransmission, motor behaviour, neuronal plasticity, and neurocognitive functions including learning and memory. Specifically, performance of music by professional musicians increased the expression of FOS, DUSP1, SNCA, catecholamine biosynthesis, and dopamine metabolism (Kanduri et al, 2015b). Interestingly, SNCA, FOS and DUSP1 are involved in song perception and production in songbirds. Thus, both listening and performing music shared partially the same genes as those affected in songbird singing. It is noteworthy that although the brains of songbirds are small they have a double density neuron structure compared to primate brains of the same mass. Thus, the large number of neurons can contribute to the neural basis of cognitive capacity (Enard 2016).

In both listening and performing music (Kanduri et al., 2015a, 2015b) one of the strongest activations was detected in the alfa-synuclein gene (SNCA), which has a physiological role in the development of nerve cells and releases neurotransmitters, especially dopamine from the presynaptic cells (Schulz-Schaeffer, 2010). Dopamine is responsible for motor functions and genes known to affect growth and the plasticity of nerve cells and the inactivation of genes affecting neurodegeneration (Kanduri et al., 2015b). SNCA is located in the best linkage region of musical aptitude on chromosome 4q22.1 and is regulated by GATA2 residing at 3q21, the region with the most significant association with musical aptitude thus linking the results of the GWA- study and transcriptional profiling studies to the same locus (Oikkonen et al., 2015; Kanduri et al., 2015a, 2015b) (Figure 4). GATA2 is abundantly expressed in dopaminergic neurons and binds to intron-1 of endogenous neuronal SNCA to regulate its expression. The results are in agreement with neurophysiological studies where increases in endogenous dopamine have been detected in the striatum when listening to music (Blood \& Zatorre 2001). Interestingly, SNCA is a causative gene for Parkinson's disease (with disturbed dopamine metabolism) (Petrucci et al, 2016) and variations in SNCA predispose to Lewy-body dementia (Peuralinna et al, 2008). 


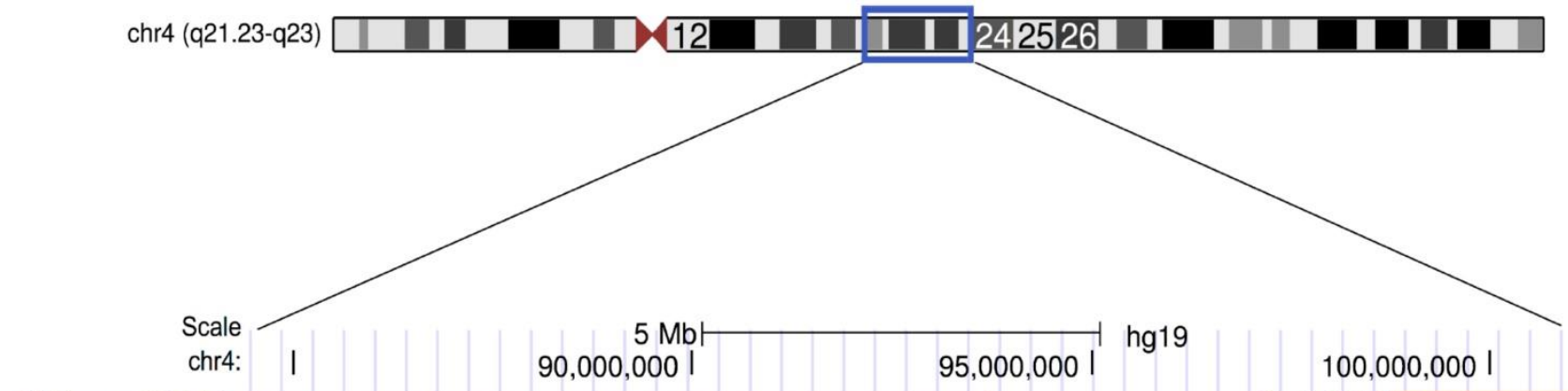

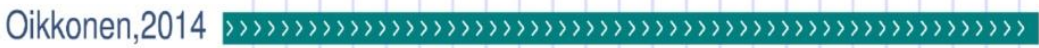

Park,2012 $\gg\rangle>>>\rangle>\rangle>\rangle>\rangle$

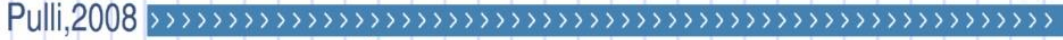

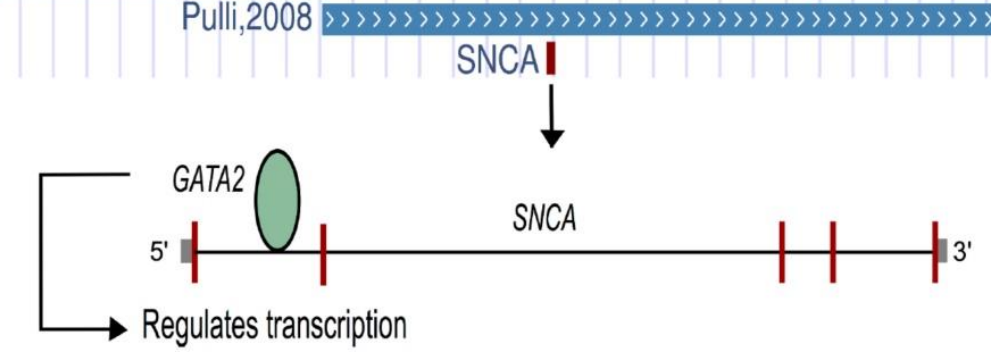

Figure 3. The results of DNA- and RNA-studies of music-related traits converge at chromosome 4q22. The alpha-synuclein gene (SNCA) upregulated by listening to music (Kanduri 2015a) and music performance by professional musicians (Kanduri 2015b) is located at the most significant region of musical aptitude (Pulli et al 2008; Park et al 2012; Oikkonen et al 2015) and regulated by GATA2, associated with musical aptitude (Oikkonen et al 2015).

Listening to music and music performance had partially different effects on gene expression. Some genes such as ZNF223 and PPP2R3A were down-regulated after music listening but up-regulated after music performance (Kanduri et al 2015a; Kanduri et al, 2015b). ZNF223 is a zinc-finger transcription regulator and similar to an immediate early response gene (IEG) ZNF225 (also known as ZENK, EGRl) that regulates the song control system of songbirds (Dong \& Clayton 2008). $P P P 2 R 3 A$, abundantly expressed in the striatum, is known to integrate the effects of dopamine and other neurotransmitters (Ahn, et al, 2007). Other IEGs such as FOS and DUSP1 that are known to be responsible for the song control nuclei of songbirds were up-regulated only after music performance (Kanduri et al, 2015b), but not music listening (Kanduri et al, 2015a). Many other song perception-related genes in songbirds like RGS2 were found to be differentially regulated after listening to music, but not after music performance (Kanduri et al 2015a; Kanduri et al, 2015b). The reasons for the differences are plausibly due to e.g. different type of musical activity and different study subjects. 
At the molecular level, auditory perception processes have been shown to exhibit convergent evolution across species (Sotomayor et al, 2012; Zhang et al, 2014). Among them is protocadherin15 (PCDH15), also found in human genome-wide association study of musical aptitude (Oikkonen et al. 2015). Also, gene expression specializations have been detected in the regions of brain that are essential for auditory perception and production, both in humans and songbirds (Pfenning et al, 2014; Salimpoor et al 2011; Whitney et al, 2014).

\section{Convergent analysis}

Integration of data from various species helps to prioritize genes most relevant to the phenotype. A rich literature exists about genes affecting the vocal learning of different species, especially songbirds (Clayton 2013; Pfenning et al. 2014) and recently, data has been gathered about candidate genes associated with human musical traits (Park 2012; Pulli 2008; Oikkonen 2015; Kanduri 2016a, 2016b; Liu et al 2016). When ranking the hitherto known data about the candidate genes found in musical aptitude, music listening, and performance with genes identified in vocalizing animal species, data about brain and tissue specific molecules and pathways can be utilized, which is not possible in human studies alone. Convergent analysis of genes identified in vocalizing animals and human music-related traits revealed that the most common candidate genes were activity dependent immediate early genes (IEGs) including EGRl, FOS, ARC, BDNF and DUSPI (Oikkonen et al, 2016). IEGs respond to sensory and motor stimuli in the brain. Of these, EGRl is widely expressed in brain regions that affect cognition, emotional response and sensitivity to reward in the rat (Duclot \& Kabbaj 2017). EGRl is upregulated by song perception and production in songbirds (Avey et al, 2008; Drnevich, et al, 2012). Interestingly, EGRl is the only highly ranked gene in all human phenotypes like music listening, music performing and musical aptitude. In contrast, PHIP, noradrenalin and NR4A2 were ranked among the top molecules in the whole sample as well as within music listening studies, but not within music performance (e.g. singing) related studies, whereas DUSP1, PKIA and DOPEY2 were the top genes specifically in music practice. These results support at least partially different molecular backgrounds for music-related processes. FOS and DUSP 1 were activated when professional musicians played a concert (Kanduri 2015a). Other candidate genes like FOXP2 and GRIN2B have been shown to be critical for vocal communication in songbirds (Haesler et al, 2004) and cognitive development including speech in humans (Hu et al 2016) and they are located in the selection regions for musical aptitude (Liu et al, 2016). There are 
still limitations in comparative studies as the avian genomes contain only $\sim 70 \%$ of the number of the human genes (Zhang et al 2014).

Convergent evidence for genes involved in functions like cognition, learning, memory have been all reported in music-related activities (Liu et al, 2016). Several pathways were identified describing the interaction and function of the identified genes. Among them, the CDK5 signalling pathway regulates cognitive functions in the brain. Interestingly, the $M E K$ gene, a member of the CDK5 signalling pathway is necessary for song learning in songbirds (London \& Clayton 2008). There is a partially shared genetic predisposition for musical abilities and general cognition (Mosing et al, 2014; Mosing et al, 2016). Human cognitive capacity has evolved rapidly, therefore it is highly likely that human-specific pathways and genes may underlie human musical abilities.

Obviously, cognition related genes are a plausible group of candidate genes for elucidating the more recent evolution of music-related traits.

\section{Biological background of creative activities in music}

Creativity in music is essential part of the development of music culture and industry. Creative activity in music, composing, improvising or arranging is common (Oikkonen et al 2016).

Some evidence for the biological basis of creativity in music has been obtained from brain imaging studies where composing (Brown et al. 2012) and improvising musical pieces are shown to affect several regions in the brain such as the medial prefrontal cortex, premotor areas and auditory cortex (Limb et al 2008; Dietrich and Kanso 2010; Liu et al 2012). Listening to music has been shown to increase dopamine in a human PET study (Salimpoor 2011).

So far, genomics approaches have been rarely applied to creative activities in general or specifically in musical activities. Dopaminergic genes appeared to be upregulated in genomic studies of musical aptitude and related traits (Oikkonen et al, 2015; Kanduri et al, 2016a; Kanduri et al, 2016b), some of them, such as FOS and FOXP2 have also been found in songbirds (Murugan et al 2013; Nordeen et al 2009). The dopamine D4 receptor gene (DRD4) is an interesting candidate for creativity in music. It mediates dopamine signalling at the neuronal synapses. Two of its signalling variants (7R and $2 \mathrm{R}$ ) have been associated not only with novelty seeking and altruism, but also financial risk taking and heavy drinking: This kind of behaviour can be seen as a sensitivity towards the influences from the environment (Kitayama et al 2016). It may be that the carriers of the $7 \mathrm{R} / 2 \mathrm{R}$ 
variants have the capacity to adopt new ways of behaviour such as to create new music (Kitayama et al 2016) (Fig. 4). This may serve as an example how genetic variants can affect culture evolution (Kim and Sasaki 2014). In fact, many composers are known to have composed music describing the actual occurrences in the society.

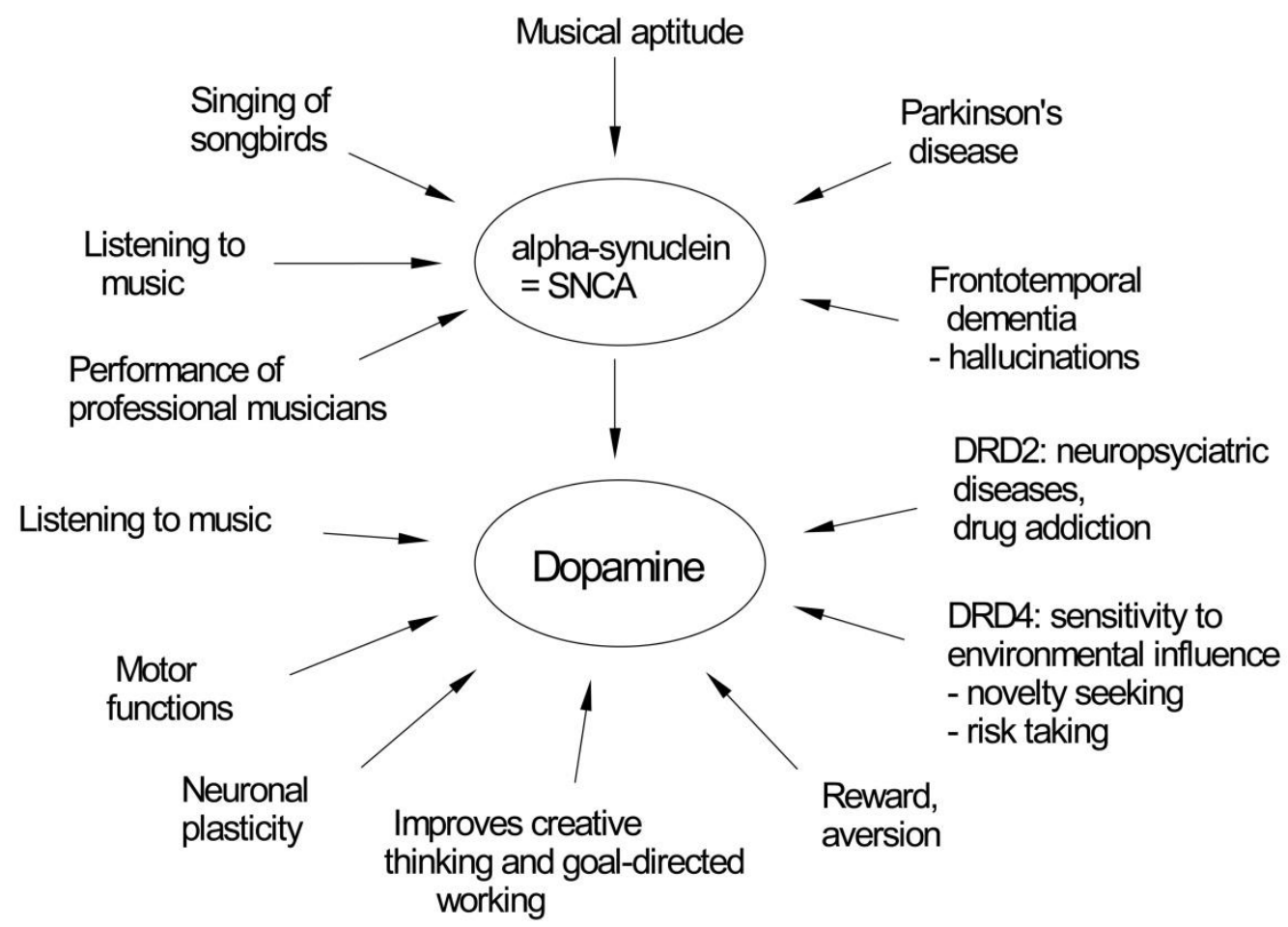

Figure 4. Several music-related traits are found to be linked to dopaminergic metabolism.

Based on a large epidemiological study from Sweden, individuals in creative professions were more likely to suffer from bipolar disorder (Kyaga et al 2011) and creative professions were overrepresented among the first-degree relatives of patients with neuropsychiatric disorders (e.g. schizophrenia and bipolar disorder) indicating familial co-segregation of creativity and neuropsychiatric disorders (Kyaga et al 2013). When the known genes and alleles associated with neuropsychiatric disorders (Lee et al 2013; Schizophrenia Working Group of the Psychiatric Genomics Consortium 2014) were analysed among artistic professions including musicians, the risk alleles were more prevalent in the artistic professions (Power et al 2016). When professional musicians played a traditional classic concert several genes reported to be mutated in neuropsychiatric or neurodegenerative diseases were be affected (Kanduri et al 2015b). This finding may reflect creative activities plausibly linked to the music performance. Thus, molecular 
genetic studies give evidence that artistic creativity and neuropsychiatric disorders are partially shared by the same predisposing genetic variants. Creativity is likely rewarding whereas diseases cause suffering. It is currently not known which of the numerous risk alleles of neuropsychiatric disorders are required and which are the individual family and environmental protective or risk factors that underlie the complex phenotype like creativity and neuropsychiatric disorders.

\section{Conclusions}

Empirical research on the biological background of music-related human traits has been introduced using genomics methods. Genes affecting inner-ear development, dopaminergic systems, learning and memory were found as candidate genes for musical aptitude, listening and performing music. In addition, the several genes previously known to affect vocal learning of songbirds were identified as candidate genes for music perception and practice. Activity dependent immediate early genes (IEGs) were the most commonly ranked genes by humans and songbirds in convergent analysis. IEGs like EGRl are critical mediators of gene-environment interactions characterized by rapid and dynamic responses to neuronal activity and reward related synaptic plasticity (Duclot \& Kabbaj 2017), also reported in music-related studies (Schneider et al, 2002; Salimpoor et al., 2011). IEGs could thus serve as plausible candidate genes to mediate the effects of music as an environmental factor. Replication studies and studies using epigenomics methods are warranted to further elucidate the biological background of music-related traits. 


\section{Literature}

Ahn, J.H., Sung, J.Y., McAvoy, T., Nishi, A., Janssens, V., Goris, J., Greengard, P., Nairn, A.C. (2007). The B"/PR72 subunit mediates Ca2+-dependent dephosphorylation of DARPP-32 by protein phosphatase 2A. Proc Natl Acad Sci U S A, 104(23),9876-81. DOI:10.1073/pnas.0703589104

Alcock, K.J., Passingham, R.E., Watkins, K., Vargha-Khadem, F. (2000). Pitch and timing abilities in inherited speech and language impairment. Brain Lang,75(1),34-46. DOI:10.1006/brln.2000.2323

Ambroggi, F., Turiault, M., Milet, A., et al. (2009). Stress and addiction: glucocorticoid receptor in dopaminoceptive neurons facilitates cocaine seeking. Nat Neurosci, 12(3), 247-9. doi: $\underline{10.1038 / \mathrm{nn} .2282 .}$

Araki, M., Bandi, M.M. and Yazaki-Sukiyama, Y. (2016). Mind the gap: Neural coding of species identity in birdsong prosody. Science, 354(6317), 1282-1287. DOI: 10.1126/science.aah6799

Atik, T., Bademci, G., Diaz-Horta, O., Blanton, S.H., Tekin, M. (2017). Whole-exome sequencing and its impact in hereditary hearing loss. Genet Res (Camb), 97: e4.

doi:10.1017/S001667231500004X.

Ayub, Q., Yngvadottir, B., Chen, Y., Xue Y, Hu, M., Vernes, S.C., Fisher, S.E., Tyler-Smith, C. (2013) FOXP2 targets show evidence of positive selection in European populations. Am J Hum Genet, 92(5), 696-706. doi: 10.1016/j.ajhg.2013.03.019

Baharloo, S., Service, S.K., Risch, N., Gitschier, J, et al. (2000). Familial aggregation of absolute pitch. American Journal of Human Genetics, 67(3),755-758. doi: 10.1086/303057

Blood, A.J.\& Zatorre, R.J. (2001). Intensely pleasurable responses to music correlate with activity in brain regions implicate in reward and emotion. Proc Natl Acad Sci U S A, 98(20), 11818-11823. doi: $\underline{10.1073 / p n a s .191355898}$

Brown, S., Martinez, M.J., Parsons, L.M. (2006). Music and language side by side in the brain: a PET study of the generation of melodies and sentences. Eur J Neurosci, 23, 2791-2803. doi: $10.1111 / \mathrm{j} .1460-9568.2006 .04785$.

Cáceres M, Lachuer J, Zapala MA, Redmond JC, Kudo L, Geschwind DH, Lockhart DJ, Preuss TM, Barlow C. 2003. Elevated gene expression levels distinguish human from non-human primate brains. Proc Natl Acad Sci U S A, 100(22), 13030-5. doi: 10.1073/pnas.2135499100

Clayton, D. F.(2000). The genomic action potential. Neurobiol Learn Mem, 74, 185-216. DOI: $\underline{10.1006 / n l m e .2000 .3967}$

Clayton, D.F. 2013. The genomics of memory and learning in songbirds. Annu Rev Genomics Hum Genet 14, 45-65. DOI:10.1146/annurev-genom-090711-163809

Cross-Disorder Group of the Psychiatric Genomics Consortium 2013. Genetic relationship between five psychiatric disorders estimated from genome-wide SNPs. Nat Genet, 45(9),984-994. doi: $\underline{10.1038 / n g .2711}$ 
Dietrich, A., Kanso, R. 2010. A review of EEG, ERP, and neuroimaging studies of creativity and insight. Psychological bulletin, 136, 822-848. doi: 10.1037/a0019749

Di Pasquale, G, Davidson, B.L., Stein, C.S. et al. (2003). Identification of PDGFR as a receptor for AAV-5 transduction. Nat Med, 9, 1306-1312. DOI:10.1038/nm929

Dixon-Salazar, T.J. and Gleeson, J.G. (2010). Genetic regulation of human brain development: lessons from Mendelian diseases. Ann N Y Acad Sci, 1214, 156-67. DOI:10.1111/j.1749$\underline{6632.2010 .05819 . x}$

Drayna, D., Manichaikul, A., de Lange, M., Snieder, H. (2001). Genetic correlates of musical pitch recognition in humans. Science, 291(5510), 1969-972. DOI:10.1126/science.291.5510.1969

Duclot, F. \& Kabbaj, M. (2017). The Role of Early Growth Response 1 (EGR1) in Brain Plasticity and Neuropsychiatric Disorders. Front Behav Neurosci 11, 35. doi: 10.3389/fnbeh.2017.00035.

Elbert T, Pantev C, Wienbruch C, Rockstroh B, Taub E. (1995). Increased cortical representation of the fingers of the left hand in string players. Science, 270, 305-307.

Enard, W., Przeworski, M., Fisher, S.E., Lai, C.S., Wiebe, V., Kitano,T., Monaco, A.P., Pääbo, S. (2002). Molecular evolution of FOXP2, a gene involved in speech and language. Nature, 418, 86972. DOI:10.1038/nature01025

Enard W. (2016). The Molecular Basis of Human Brain Evolution. Curr Biol, 26(20), R1109R1117. doi: 10.1016/j.cub.2016.09.030.

Fatemi SH, Folsom TD, Rooney RJ, Thuras PD. (2013).Expression of GABAA a2-, b1- and ereceptors are altered significantly in the lateral cerebellum of subjects with schizophrenia, major depression and bipolar disorder. Transl Psychiatry 3, e303. doi: 10.1038/tp.2013.64.

Flaherty, A.W. (2005). Frontotemporal and dopaminergic control of idea generation and creative drive. J Comp Neurol, 493(1), 147-153. doi:10.1002/cne.20768.

Flaherty, A.W. (2011). Brain illness and creativity: mechanisms and treatment risks. Can J Psychiatry 56(3):132-43. Review. DOI:10.1177/070674371105600303

Gaser, C., Schlaug, G. (2003). Brain structures differ between musicians and non-musicians. J Neurosci, 23(27),9240-5.

George, J. M., Jin, H., Woods, W. S. \& Clayton, D. F. (1995). Characterization of a novel protein regulated during the critical period for song learning in the zebra finch. Neuron, 15, 361-72. 10.1016/0896-6273(95)90040-3

Gosselin, N., Peretz, I., Johnsen, E. and Adolphs R. (2007). Amygdala damage impairs emotion recognition from music. Neuropsychologia 45, 236-244.

DOI:10.1016/j.neuropsychologia.2006.07.012

Greene, J.G. (2006). Gene expression profiles of brain dopamine neurons and relevance to neuropsychiatric disease. J Physiol 575, 411-6. DOI:10.1113/jphysiol.2006.112599 
Guo, Y.P., Sun, X., Li, C., Wang, N.Q., Chan, Y.S., He, J., (2007). Corticothalamic synchronization leads to c-fos expression in the auditory thalamus. Proc. Natl. Acad. Sci. U. S. A,. 104, 11802-7. DOI:10.1073/pnas.0701302104

Haugas, M., Lilleväli, K., Hakanen, J., Salminen, M. (2010). Gata2 is required for the development of inner ear semicircular ducts and the surrounding perilymphatic space. Dev Dyn, 239, 2452-2469. DOI: $10.1002 /$ dvdy.22373

Haesler, S., Wada, K., Nshdejan, A., Morrisey, E.E., Lints, T., Jarvis, E.D., Scharff, C.(2004). FoxP2 expression in avian vocal learners and non-learners. J Neurosci, 24(13), 3164-75. DOI: 10.1523/JNEUROSCI.4369-03.2004

Hambrick D. Z., Oswald F. L., Altmann E. M., Meinz E. J., Gobet F., Campitelli G. 2014. Deliberate practice: Is that all it takes to become an expert? Intelligence, 45, 34-45. https://doi.org/10.1016/j.intell.2013.04.001

Hennessey, B.A., Amabile, T.M. (2010). Creativity. Annu Rev Psychol, 61,569-598. doi: 10.1146/annurev.psych.093008.100416

Herholz, S. C. and Zatorre, R. J. (2012). Musical training as a framework for brain plasticity: behavior, function, and structure. Neuron, 76, 486-502. doi: 10.1016/j.neuron.2012.10.011.

Hertel, N., Redies, C., Medina, L. (2012). Cadherin expression delineates the divisions of the postnatal and adult mouse amygdala. J Comp Neurol, 520, 3982-4012. doi: 10.1002/cne.23140.

Hilliard, A.T., Miller, J.E., Fraley, E.R., Horvath, S., White, S.A. (2012). Molecular microcircuitry underlies functional specification in a basal ganglia circuit dedicated to vocal learning. Neuron, 73(3),537-52. doi: 10.1016/j.neuron.2012.01.005

Honing, H., Ten Cate, C., Peretz, I. and Trehub, S. E. 2015. Without it no music: cognition, biology and evolution of musicality. Philos Trans R Soc Lond B Biol Sci, 370(1664):20140088. doi: $\underline{10.1098 / \text { rstb.2014.0088. }}$

Horita, H. et al. (2012). Specialized motor-driven dusp1 expression in the song systems of multiple lineages of vocal learning birds. PLoS One 7, e42173.

Hu, C., Chen, W., Myers, S.J., Yuan, H., Traynelis, S.F.(2016). Human GRIN2B variants in neurodevelopmental disorders. J Pharmacol Sci, 132(2),115-121. doi: 10.1016/j.jphs.2016.10.002.

Justus, T. and Hustler, J.J. (2005). Fundamental issues in the evolutionary psychology of music: Assessing innateness and domain specificity. Music Perception, 23, 1-27.

doi:10.1525/mp.2005.23.1.1.

Kanduri, C., Raijas, P., Ahvenainen, M., Philips, A.K., Ukkola-Vuoti, L., Lähdesmäki, H., Järvelä, I (2015). The effect of listening to music on human transcriptome. PeerJ, 3:e830.

https://doi.org/10.7717/peerj.830

Kanduri, C., Kuusi, T., Ahvenainen, M., Philips, A.K., Lähdesmäki, H., Järvelä, I. (2015).The effect of music performance on the transcriptome of professional musicians. Sci Rep, 5,9506.

doi: $\underline{10.1038 / \text { srep09506 }}$ 
Karma, K. (1994). Auditory and Visual Temporal Structuring: How Important is Sound to Musical Thinking? Psychology of Music, 22, 20-30. https://doi.org/10.1177/0305735694221002

Katori, S., Hamada, S., Noguchi, Y., Fukuda, E., Yamamoto, T., Yamamoto, H., Hasegawa, S., Yagi, T.(2009). Protocadherin-alpha family is required for serotonergic projections to appropriately innervate target brain areas. J Neurosci, 29(29),9137-47. doi: 10.1523/JNEUROSCI.5478-08.2009.

Katz, E., Elgoyhen, A.B., Gómez-Casati, M.E. et al. (2004). Developmental regulation of nicotinic synapses on cochlear inner hair cells. J Neurosci., 24, 7814-7820. DOI:10.1523/JNEUROSCI.2102$\underline{04.2004}$

Kim, H.S. and Sasaki, J.Y. (2014). Cultural Neuroscience: Biology of the Mind in Cultural Contexts. Annu Rev Psychol 65,487-514. doi10.1146/annurev-psych-010213-115040

Kitayama, S., King, A., Hsu, M., Liberzon, I., Yoon, C. (2016). Dopamine-System Genes and Cultural Acquisition: The Norm Sensitivity Hypothesis. Curr Opin Psychol. 8,167-174. doi: $\underline{10.1016 / j . c o p s y c .2015 .11 .006 . ~}$

Koelsch, S. (2010). Towards a neural basis of music-evoked emotions. Trends Cogn Sci, 14, 131137. doi: 10.1016/j.tics.2010.01.002.

Kyaga, S., Lichtenstein, P., Boman, M., Hultman, C., Långström, N., Landén, M. (2011). Creativity and mental disorder: family study of 300,000 people with severe mental disorder. Br J Psychiatry 199(5):373-9. doi: 10.1192/bjp.bp.110.085316.

Kyaga, S., Landén, M., Boman, M., Hultman, C.M., Långström, N., Lichtenstein, P. (2013).

Mental illness, suicide and creativity: 40-year prospective total population study. J Psychiatr Res. 47(1),83-90. doi: 10.1016/j.jpsychires.2012.09.010.

Lahti, L., Achim, K., Partanen, J. (2013). Molecular regulation of GABAergic neuron differentiation and diversity in the developing midbrain. Acta Physiol (Oxf), 207, 616-627. doi: $\underline{10.1111 / a p h a .12062}$

Lai, C.S., Fisher, S.E., Hurst, J.A., Vargha-Khadem, F., Monaco, A.P. (2001). A forkhead-domain gene is mutated in a severe speech and language disorder. Nature,413(6855),519-23.DOI:

$\underline{10.1038 / 35097076}$

Lammel, S., Lim, B.K., Malenka, R.C. (2014). Reward and aversion in a heterogeneous midbrain dopamine system. Neuropharmacology 76, 351-359. doi:10.1016/j.neuropharm.2013.03.019.

Lander, E.S. (2011). Initial impact of the sequencing of the human genome. Nature, 470,187-197. doi: $10.1038 / 09792$

Levitin, D.J. (2012). What does it mean to be musical? Neuron, 73,633-637. doi: 10.1016/j.neuron.2012.

Limb, C.J., Braun, A.R. (2008). Neural substrates of spontaneous musical performance: an FMRI study of jazz improvisation. PLoS One 3,e1679. doi: 10.1371/journal.pone.0001679 
Liu, S., Chow, H.M., Xu,Y., et al.(2012). Neural correlates of lyrical improvisation: an FMRI study of freestyle rap. Sci Rep 2,834. doi: 10.1038/srep00834

Lin, J., Yan, X., Wang, C. et al. (2012). Anatomical expression patterns of delta-protocadherins in developing chicken cochlea. J Anat 221, 598-608. doi: 10.1111/j.1469-7580.2012.01568.X

Lindor, N.M., Thibodeau, S. and Burke, W. (2017). Whole-genome sequencing in healthy people. Mayo Clinic Proceedings, 92(1), 159-172. DOI: 10.1016/j.mayocp.2016.10.019

Lipkind, D. \& Tchernichovski, O. (2011). Colloquium Paper: Quantification of developmental birdsong learning from the subsyllabic scale to cultural evolution. Proc. Natl. Acad. Sci, 108, 15572-15579. https://doi.org/10.1073/pnas.1012941108

Liu, X., Kanduri, C., Oikkonen, J., Karma, K., Raijas, P., Ukkola-Vuoti, L., Teo, Y-Y., Järvelä, I. (2016). Detecting signatures of positive selection associated with musical aptitude in the human genome. Sci Rep, 6,21198. doi: 10.1038/srep21198.

de Manzano, Ö., Cervenka, S., Karabanov, A., Farde, L., Ulle’n, F. (2010). Thinking Outside a Less Intact Box: Thalamic Dopamine D2 Receptor Densities Are Negatively Related to Psychometric Creativity in Healthy Individuals. PLoSONE, 5, e10670. doi:10.1371/journal.pone.0010670

Martínez-Molina, N., Mas-Herrero, E., Rodríguez-Fornells, A, Zatorre, R.J., Marco-Pallarés, J. (2016) Neural correlates of specific musical anhedonia. Proc Natl Acad Sci U S A, 113(46), E7337E7345.

Mayseless, N., Uzefovsky, F., Shalev, I., Ebstein, R.P., Shamay-Tsoory, S.G. (2013). The association between creativity and 7R polymorphism in the dopamine receptor D4 gene (DRD4). Front Hum Neurosci 7,502. doi: 10.3389/fnhum.2013.00502.

Metz M, Gassmann M, Fakler B, Schaeren-Wiemers N, et al. (2011). Distribution of the auxiliary GABAB receptor subunits KCTD8, 12, 12b, and 16 in the mouse brain. J Comp Neurol, 519, 14351454. DOI: $10.1002 /$ cne.22610

Montealegre-Z, F., Jonsson, T., Robson-Brown, K. A., Postles, M. \& Robert, D. (2012). Convergent evolution between insect and mammalian audition. Science 338, 968-71. doi: $\underline{10.1126 / \text { science. } 1225271 .}$

Mosing, M.A., Madison, G., Pedersen, N.L., Kuja-Halkola, R., Ullén, F. 2014. Practice does not make perfect: no causal effect of music practice on music ability. Psychol Sci, 25(9),1795-803.doi: $\underline{10.1177 / 0956797614541990 .}$

Murugan, M.., Harward, S., Scharff, C. \& Mooney, R. (2013). Diminished FoxP2 levels affect dopaminergic modulation of corticostriatal signaling important to song variability. Neuron, 80 , 1464-1476. doi: 10.1016/j.neuron.2013.09.021.

Nakahara, H., Masuko, T., Kinoshita, H., Francis, P. R. and Furuya, S. (2011). Performing music can induce greater modulation of emotion-related psychophysiological responses than listening to music. Int J Psychophysiol 81, 152-158. doi: 10.1016/j.ijpsycho.2011.06.003. 
Nordeen, E.J., Holtzman, D.A., Nordeen, K.W. (2009). Increased Fos expression among midbrain dopaminergic cell groups during birdsong tutoring. Eur J Neurosci, 30(4),662-70. doi: 10.1111/j.1460-9568.2009.06849.x.

Oikkonen, J. \& Järvelä, I. (2014). Genomics approaches to study musical aptitude. Bioessays, 36(11):1102-8. doi: 10.1002/bies.201400081.

Oikkonen, J., Huang, Y., Onkamo, P., Ukkola-Vuoti, L., Raijas, P., Karma, K., Vieland, V.J., Järvelä, I. (2015). A genome-wide linkage and association study of musical aptitude identifies loci containing genes related to inner ear development and neurocognitive functions. $\mathrm{Mol}$ Psychiatry,20(2):275-82. doi: 10.1038/mp.2014.8.

Oikkonen, J., Onkamo, P., Järvelä, I. and Kanduri, C. (2016). Convergent evidence for the molecular basis of musical traits. Sci Rep, 6, 39707. doi: 10.1038/srep39707

Ousdal, O.T., Anand Brown, A., Jensen, J. et al. (2012). Associations between variants near a monoaminergic pathways gene (PHOX2B) and amygdala reactivity: a genome-wide functional imaging study. Twin Res Hum Genet, 15, 273-285. doi: 10.1017/thg.2012.5.

Park, H., Lee, S., Kim, H.J., Ju, Y.S. (2012). Comprehensive genomic analyses associate UGT8 variants with musical ability in a Mongolian population. J Med Genet, 49, 747-752. doi: 10.1136/jmedgenet-2012-101209.

Parker, J., Tsagkogeorga, G., Cotton, J.A., Liu, Y., Provero, P., Stupka, E., Rossiter, S.J. (2013). Genome-wide signatures of convergent evolution in echolocating mammals. Nature, 502, 228-31. doi: $10.1038 /$ nature 12511

Perani, D., Saccuman, M.C., Scifo, P. et al. (2010). Functional specializations for music processing in the human newborn brain. Proc Natl Acad Sci U S A, 107, 4758-4763.

doi: $10.1073 /$ pnas.0909074107

Peretz, I., Cummings, S., Dube, M.P. (2007). The genetics of congenital amusia (tone deafness): a family-aggregation study. American Journal of Human Genetics, 81(3), 582-588.

DOI: $10.1086 / 521337$

Petrucci, S., Ginevrino, M., Valente, E.M. (2016). Phenotypic spectrum of alpha-synuclein mutations: New insights from patients and cellular models. Parkinsonism Relat Disord 22 Suppl 1:S16-20. doi: 10.1016/j.parkreldis.2015.08.015.

Peuralinna, T., Oinas, M., Polvikoski, T., et al. (2008). Neurofibrillary tau pathology modulated by genetic variation of alpha-synuclein. Ann Neurol 64(3),348-52. doi: 10.1002/ana.21446.

Pfenning, A.R., Hara, E., Whitney, O. et al. (2014). Convergent transcriptional specializations in the brains of humans and song-learning birds. Science 346:1256846-1256846. DOI:

$\underline{10.1126 / \text { science. } 1256846}$ 
Penhune, V. and de Villers-Sidani, E. (2014). Time for new thinking about sensitive periods. Front Syst Neurosci, 8,55. doi: 10.3389/fnsys.2014.00055.

Power, R.A, Steinberg, S., Bjornsdottir, G, et al. (2015). Polygenic risk scores for schizophrenia and bipolar disorder predict creativity. Nat Neurosci 18(7), 953-5. doi: 10.1038/nn.4040.

Pulli, K., Karma, K., Norio, R., Sistonen, P., Göring, H.H., Järvelä, I. (2008). Genome-wide linkage scan for loci of musical aptitude in Finnish families: evidence for a major locus at 4q22. $J$ Med Genet,45(7),451-6. doi: 10.1136/jmg.2007.056366.

Qian, W., Deng, L., Lu, D. \& Xu, S. (2013). Genome-Wide Landscapes of Human Local Adaptation in Asia. PLoS One 8 (1): e54224. doi.org/10.1371/journal.pone.0054224

Raghanti „M.A., Edler, M.K., Stephenson, A.R., Wilson, L.J., Hopkins, W.D., Ely, J.J., Erwin, J.M., Jacobs, B., Hof, P.R., Sherwood, C.C. 2016.Human-specific increase of dopaminergic innervation in a striatal region associated with speech and language: A comparative analysis of the primate basal ganglia. J Comp Neurol,524(10),2117-29. doi: 10.1002/cne.23937.

Rothenberg, D., Roeske, T.C., Voss, H.U., Naguib, M. and Tchernichovski, O. (2014). Investigation of musicality in birdsong. Hear Res, 308, 71-83. doi: 10.1016/j.heares.2013.08.016.

Sabeti, P. C., Schaffner, S.F., Fry, B. et al (2006). Positive natural selection in the human lineage. Science, 312, 1614-1620.DOI:10.1126/science.1124309

Salimpoor, V.N., Benovoy, M., Longo, G., Cooperstock, J.R., Zatorre, R.J. (2009). The rewarding aspects of music listening are related to degree of emotional arousal. PLOS ONE 4. doi: 10.1371/journal.pone.0007487

Salimpoor, V.N., Benovoy, M., Larcher, K., Dagher, A., Zatorre, R.J. (2011). Anatomically distinct dopamine release during anticipation and experience of peak emotion to music. Nat Neurosci, 14(2), 257-62. doi: 10.1038/nn.2726.

Salimpoor, V.N., Zald, D.H., Zatorre, R.J., Dagher, A. and McIntosh, A.R. (2015). Predictions and the brain: how musical sounds become rewarding. Trends Cogn Sci,19(2), 86-91. doi:

$\underline{10.1016 / j . t i c s .2014 .12 .001 .}$

Scherzer, C.R., Grass, J.A, Liao, Z. et al. (2008). GATA transcription factors directly regulate the Parkinson's disease-linked gene alpha-synuclein. Proc Natl Acad Sci USA, 105, 10907-10912. doi: $\underline{10.1073 / \text { pnas.0802437105. }}$

Schizophrenia Working Group of the Psychiatric Genomics C. (2014). Biological insights from 108 schizophrenia-associated genetic loci. Nature 511, 421-427. doi: 10.1038/nature13595.

Seashore, C., Lewis, D.. Saetveit, J. (1960). Seashore Measures of Musical Talents (Manual). The Psychological Corp; New York, USA.

Shah, K. \& Lahiri, D.K. (2014). Cdk5 activity in the brain - multiple paths of regulation. $J$ Cell Sci, 127, 2391-2400. doi: 10.1242/jcs.147553. 
Sotomayor, M., Weihofen, W.A., Gaudet, R., Corey, D.P. (2012). Structure of a force-conveying cadherin bond essential for inner-ear mechanotransduction. Nature, 492, 128-132. doi: $\underline{10.1038 / \text { nature } 11590}$

Theusch, E., Basu, A., Gitschier, J. (2009)Genome-wide study of families with absolute pitch reveals linkage to 8q24.21 and locus heterogeneity. Am J Hum Genet ,85(1),112-9. doi: 10.1016/j.ajhg.2009.06.010.

Ukkola-Vuoti, L., Kanduri, C., Oikkonen, J. et al. (2013). Genome-wide copy number variation analysis in extended families and unrelated individuals characterized for musical aptitude and creativity in music. PLoS ONE, 8, e56356. doi: 10.1371/journal.pone.0056356

Vernes, S.C., Spiteri, E., Nicod, J., Groszer, M., Taylor, J.M., Davies, K.E, Geschwind, D.H., Fisher, S.E.(2007). High-throughput analysis of promoter occupancy reveals direct neural targets of FOXP2, a gene mutated in speech and language disorders. Am J Hum Genet; 81(6),1232-50.

DOI: $\underline{10.1086 / 522238}$

White, E.J., Hutka, S.A., Williams, L.J. and Moreno, S. (2013).Learning, neural plasticity and sensitive periods: implications for language acquisition, music training and transfer across the lifespan. Front Syst Neurosci, 7, 90. doi: 10.3389/fnsys.2013.00090

Wood WE, Olson CR, Lovell PV, Mello CV. 2008. Dietary retinoic acid affects song maturation and gene expression in the song system of the zebra finch. Dev Neurobiol.,68(10),1213-24. doi: 10.1002/dneu.20642.

Zhang, G., Li, C., Li, G. et al. (2014). Comparative genomics reveals insights into avian genome evolution and adaptation. Science 346, 1311-1320. doi: $10.1126 /$ science.1251385 